\title{
AS PESSOAS COM ALBINISMO E O DIREITO À SAÚDE NO BRASIL
}

PEOPLE WITH ALBINISM AND THE RIGHT TO HEALTH IN BRAZIL

Joselito Pereira da Luz *

\section{Resumo}

Este artigo objetivou analisar, à luz da constituição e da legislação infraconstitucional, a problemática acerca do direito das pessoas com albinismo frente ao dever do Estado de garantir políticas públicas de acesso à saúde de forma integral e específica. Para tanto, com fundamento nos princípios constitucionais, buscou-se mapear as diretrizes, leis e normas que regulam as ações públicas de saúde de caráter e específico, levantando as principais ações públicas em andamento. Ainda procurou identificar as principais possibilidades e dificuldades enfrentadas no acesso ao direito à saúde em relação às pessoas com albinismo.

Palavras-chave: saúde; albinismo; pessoa com deficiência; políticas públicas.

\begin{abstract}
This is a study that aimed to carry out an evaluation on whether existing public health actions aimed at people with disabilities, with pathologies, and with rare diseases, also contemplate people with albinism. Therefore, based on constitutional principles, we sought to map the guidelines, laws and norms that regulate public health actions of a general and specific nature, raising the main public actions in progress, identifying the main difficulties faced in accessing the right to health.
\end{abstract}

Keywords: health; albinism; person disabilities; public policies.

\section{Introdução}

Este texto é resultado do artigo apresentado na conclusão do Curso de Direito da Faculdade de Tecnologia e Ciências (UNIFTC) no segundo semestre de 2020. O objetivo principal foi analisar, à luz da Constituição Federal de 1988 (CF) e da legislação infraconstitucional, a problemática acerca do direito das pessoas com albinismo frente ao dever do Estado de garantir políticas públicas de acesso à saúde de forma integral e específica. Para tanto, com fundamento nos princípios constitucionais, buscou-se mapear as diretrizes, leis e normas que regulam as ações públicas de saúde de caráter geral e específico, levantando as principais ações públicas em andamento; identificar as principais possibilidades e dificuldades enfrentadas no acesso ao direito à saúde em relação

\footnotetext{
* Bacharel em Direito pela Faculdade de Tecnologia e Ciências (UniFTC)/Brasil. E-mail: zelito.luz@gmail.com.
} 
à pessoa com albinismo, com ênfase na atenção integral articulada com as ações de promoção, prevenção e assistência; acesso aos medicamentos essenciais conforme protocolos médicos; promoção orientação e aconselhamento genético às pessoas acometidas pelo albinismo e seus familiares, e política de educação permanente em saúde.

A escolha do tema se justifica pela necessidade de dar publicidade ao sofrimento das pessoas acometidas pelo albinismo decorrente da precariedade no atendimento pelo serviço público de saúde, não só pela inexistência de políticas públicas específicas, mas também pela insuficiência de recursos e meios próprios para prover as ações de prevenção e tratamento das sequelas, especialmente quanto ao câncer de pele, à fotofobia, à visão subnormal (baixa visão) e, em alguns casos, à cegueira.

Vários países, inclusive o Brasil, reunidos na primeira conferência sobre promoção da saúde, realizada em 1986, na cidade de Ottawa, no Canadá, estabeleceram que a saúde deve ser vista como um recurso para a vida, e não como objetivo de viver. Nesse sentido, a saúde é um conceito positivo, que enfatiza os recursos sociais e pessoais, bem como as capacidades físicas. Assim, a promoção de políticas públicas da saúde não é responsabilidade exclusiva do setor saúde, e vai para além de um estilo de vida saudável, na direção de um bem-estar global. Percebe-se, no fragmento supracitado da Carta da Conferência, uma concepção mais ampla de saúde atrelada a uma dimensão fundamental da vida que deve contribuir para o bem-estar da população como um todo e que não deve se restringir apenas ao bem-estar individual ou de forma restrita a certas localidades.

Em que pese a CF de 1988 definir a saúde como um direito humano fundamental, além do fato de existirem diretrizes, princípios, e determinações para que o Estado assegure aos usuários do sistema público de saúde uma ampla e integrada rede de proteção à saúde, percebe-se uma carência na oferta de serviços de atenção básica, de média complexidade, e de alta complexidade, especialmente àqueles serviços que estejam relacionados ao atendimento das necessidades das pessoas com albinismo. A CF de 1988, antes de prever o direito à saúde, estabeleceu como fundamento a cidadania e a dignidade da pessoa humana, algo que somente se consolida quando aquele direito básico for assegurado para todos os cidadãos numa relação de igualdade e de especificidade, não se permitindo a exclusão de nenhum ser humano, incluindo aquele que possui algum tipo de deficiência. 
O albinismo é um fenômeno genético, caracterizado pela inexistência ou insuficiência de melanina, proteína responsável pela pigmentação da pele, pelos, cabelos e olhos. Como consequência da deficiência da melanina, as pessoas acometidas pelo albinismo podem sofrer agravos, na pele (lesões pré-malignas ou malignas) quando expostas aos raios solares, e na visão (deficiência visual), decorrente da visão subnormal também conhecida como baixa visão. A pessoa com albinismo pode apresentar diferentes graus de deficiência visual, classificada de acordo com os valores de acuidade visual corrigida no melhor olho. Frequentemente ocorre estrabismo, com prejuízo na percepção de profundidade pela falta de coordenação entre os olhos, fotofobia e nistagmo, devido aos movimentos rápidos e involuntários dos olhos na horizontal, o que também contribui para a baixa visão.

Dada a relevância e complexidade do tema que, além do direito à saúde no aspecto específico, também se enquadra na categoria dos direitos humanos e sociais. Este trabalho tem como propósito trazer uma contribuição à reflexão sobre as políticas públicas especificas de saúde disponibilizadas pelo poder público e sua eficácia para assegurar às pessoas os cuidados necessários à prevenção e tratamento das sequelas decorrentes do albinismo.

Neste estudo, foi objeto de análise a CF de 1988, no tocante às políticas públicas de saúde, com a observância das diretrizes e critérios sobre a aplicação dos direitos ali estabelecidos, especificamente se destaca os artigos 196 a 200 (BRASIL, 1988); Lei Orgânica da Saúde — Lei 8.080 (BRASIL, 1990); Estatuto da Pessoa com Deficiência - Lei 13.146 (BRASIL, 2015); Política Nacional de Atenção Integral em Genética Clínica - Portaria GM/MS nº 81 (BRASIL, 2009a) e; Diretrizes Para Atenção Integral às Pessoas com Doenças Raras no Sistema Único de Saúde — Portaria GM/MS no 199 (BRASIL, 2014a).

Além de visitar a legislação que trata do tema aqui abordado, pesquisou-se referências de vários autores que dissertam sobre o assunto em livros e artigos acadêmicos. Ressalte-se que na pesquisa bibliográfica realizada, observa-se uma grande carência de produção literária sobre o tema. No entanto, percebe-se um esforço muito grande de alguns graduandos, mestres e doutores na produção de pesquisas e estudos acadêmicos apresentados em trabalhos de conclusão de curso, teses de mestrado ou 
doutorado, bem como estudos científicos e laboratoriais publicados em revistas vinculadas à área da saúde. Destacando-se que, em cursos "stricto sensu", não foram localizados artigos relativos ao tema específico aqui abordado.

\title{
Caracterização e perfil do albinismo
}

Diversas pesquisas sobre o albinismo mostram que esse distúrbio genético está presente em todas as etnias, embora tenha uma prevalência aumentada entre negros. Moreira e seus colaboradores (MOREIRA; PINHEIRO; REIS; VIRGENS; GÓES, 2021) realizaram um estudo sobre a hereditariedade do albinismo oculocutâneo, em parceria com a Associação das Pessoas com Albinismo na Bahia (APALBA), e evidenciaram que:

\begin{abstract}
A incidência mundial do albinismo é de 1:20.000 indivíduos, sendo o albinismo Oculocutâneo tipo 1 (OCA1) o subtipo mais comum em populações brancas, representando cerca de $50 \%$ dos casos mundiais, enquanto o OCA2 mostra maior incidência em africanos e afrodescendentes (1:10.000) e tem sido associado à consanguinidade e, principalmente, ao efeito fundador. Nessas populações, a frequência mais elevada do albinismo faz com que o mesmo seja considerado um traço genético associado às etnias africanas (MOREIRA; PINHEIRO; REIS; VIRGENS; GÓES, 2021, p. 3-4).
\end{abstract}

O albinismo oculocutâneo ocorre quando há alterações genéticas na síntese da melanina, afetando todo o corpo devido à falta de pigmentação. Segundo o estudo citado acima (MOREIRA; PINHEIRO; REIS; VIRGENS; GÓES, 2021), o albinismo pode ser classificado de acordo com os genes associados ao distúrbio e à localização cromossômica desses genes. Os autores compreendem que o OCA1 é causado por mutação no gene tirosinase (TYR), que atua na produção da tirosina, enzima precursora da melanina, assim existe um bloqueio total da síntese de melanina; já o OCA2 é causado pela "alteração no gene OCA2 (anteriormente denominado gene P), responsável por codificar a proteína $\mathrm{P}$, cujas funções não são completamente compreendidas, mas com provável papel no transporte de proteínas e regulação do $\mathrm{pH}$ dos melanossomas" (MOREIRA; PINHEIRO; REIS; VIRGENS; GÓES, 2021, p. 1). O OCA2 é o tipo de albinismo mais comum, podendo haver bloqueio incompleto da melanina nos indivíduos afetados. 
Não existem dados oficiais acerca da população de pessoas com albinismo ou sobre a magnitude da questão no Brasil, o que torna ainda mais urgente a necessidade da realização de mapeamentos. Os poucos dados na literatura são de alguns estudos isolados, como na comunidade da Ilha de Lençóis, de 400 habitantes no Maranhão com prevalência de albinismo na região da ordem de 1,5 para cada 100 habitantes (FREIRE-MAIA, 1988), e estudo com indígenas brasileiros mostrando casos isolados em uma comunidade e a drástica diminuição de sua prevalência devido ao infanticídio (FREITAS; FREITAS; SANTOS, 2005).

$\mathrm{Na}$ Bahia, também não existem estatísticas sobre o número de pessoas com Albinismo no estado. Nesse cenário, destacamos o trabalho de Moreira e seus colaboradores (MOREIRA; BORGES; PINHEIRO; SANTA CECÍLIA, 2019), em que analisaram a distribuição de albinismo oculocutâneo em municípios da Bahia, estado com alta taxa de descendência africana, por meio de abordagem descritiva e exploratória, utilizando uma amostra de conveniência constituída por sujeitos de ambos os sexos, com idade entre 1 a 65 anos, cadastrados na Associação das Pessoas com Albinismo na Bahia (APALBA). Em resultado, os autores registraram 481 casos de albinismo em noventa municípios baianos, categorizados em mesorregiões com taxas populacionais de albinismo em 34 cidades de diferentes mesorregiões, nas quais a frequência de albinismo foi superior a 1:10.000 habitantes, que é o valor esperado para afrodescendentes.

De acordo com os dados censitários do Instituto Brasileiro de Geografia e Estatística (IBGE), (INSTITUTO BRASILEIRO DE GEOGRAFIA E ESTATÍSTICA, 2012), a Bahia é o terceiro estado mais populoso do Brasil, com um total de 14.016.906 habitantes. Salvador, a capital do estado, compreende $19 \%$ deste total e possui características demográficas peculiares, resultante de fatores socioculturais e biológicos que inseriu na sua história uma pluralidade tri-étnica de portugueses, índios e negros. A população baiana apresenta etnia predominantemente negra, decorrente do período da colonização em que era o principal centro de distribuição de escravos africanos, o que está de acordo com a forma com que a maioria dos habitantes se autodeclaram. Esse fato histórico traz importante contribuição para a frequência e distribuição nessa população de características genéticas como a anemia falciforme e o albinismo oculocutâneo tirosinase 
positiva, que de acordo com Zago (1994) e Moreira, Pinheiro, Borges e Santa Cecília (2016), são distúrbios mais frequentes na população negra.

\section{O Sistema Único de Saúde (SUS) e as políticas públicas}

A definição de princípios e diretrizes sobre o direito à saúde se observa a partir da vigência da CF de 1988, também conhecida como Constituição Cidadã, em cujo texto, logo no preâmbulo, os constituintes promulgam o compromisso de "assegurar o exercício dos direitos sociais e individuais, a liberdade, a segurança, o bem-estar, o desenvolvimento, a igualdade e a justiça como valores supremos de uma sociedade fraterna, pluralista e sem preconceitos" (BRASIL, 1988, p. 1).

Da análise do texto constitucional, pode-se afirmar que a saúde foi concebida como um princípio assecuratório do exercício da cidadania, pois em conjunto com a previdência e a assistência social, compõe o tripé que constitui o sistema de seguridade social entendida no artigo 194 da CF de 1988 como "um conjunto integrado de ações de iniciativa dos Poderes Públicos e da sociedade, destinadas a assegurar os direitos relativos à saúde, à previdência e à assistência social” (BRASIL, 1988, p. 113).

Essa concepção sintoniza com a Declaração Universal dos Direitos Humanos promulgada pela Resolução 217-A, de 10 de dezembro de 1948, da Assembleia Geral das Nações Unidas que, embora não tenha efeito vinculante, estabelece no Art. $25, \S 1^{\circ}$ que:

Toda pessoa tem direito a um padrão de vida capaz de assegurar a si e a sua família saúde e bem-estar, inclusive alimentação, vestuário, habitação, cuidados médicos e os serviços sociais indispensáveis, e direito à segurança em caso de desemprego, doença, invalidez, viuvez, velhice ou outros casos de perda dos meios de subsistência em circunstâncias fora de seu controle (ORGANIZAÇÃO DAS NAÇÕES UNIDAS, 1948, p. 4).

O SUS foi criado pela Lei 8.080, de 19 de setembro de 1990 (BRASIL, 1990), também chamada de "Lei Orgânica da Saúde", foi concebido para concretizar o princípio constitucional da saúde como direito de todos e dever do Estado, concebendo no Art. $7^{\circ}$ da norma que "as ações e os serviços públicos de saúde e os serviços privados contratados ou conveniados que integram o Sistema Único de Saúde (SUS) são desenvolvidos de 
acordo com as diretrizes previstas no art. 198 da Constituição Federal” (BRASIL, 2009a, online).

No mesmo Artigo $7^{\circ}$, incisos I a XIII, a Lei 8080/90 estabelece ainda que o SUS será fundamentado em 13 princípios, dentre os quais destacam-se a universalidade, equidade, integralidade, igualdade e autonomia da assistência à saúde, sem preconceitos ou privilégios de qualquer espécie. Para garantir o direito à saúde, o SUS foi concebido pelos legisladores constituintes como um sistema descentralizado para unificar as ações e serviços públicos de saúde, integrado por uma rede regionalizada e hierarquizada para prestar atendimento integral e atuar com a participação da comunidade, constituindo-se, portanto, como uma instituição pública fundamental para a garantia do acesso à saúde para as pessoas com deficiência, incluindo, assim, as pessoas com albinismo.

A pessoa com albinismo têm mais dificuldade de acesso às ações públicas de saúde para prevenção e tratamento das sequelas decorrentes da patologia em relação a outros segmentos da população, porque necessitam de políticas públicas específicas.

Em 07 de julho de 2015, foi publicada a Lei 13.146, que institui a Lei Brasileira de Inclusão da Pessoa com Deficiência, também nominada de Estatuto da Pessoa com Deficiência, que considera em seu Art. $2^{\circ}$, a pessoa com deficiência como aquela que “tem impedimento de longo prazo de natureza física, mental, intelectual ou sensorial, o qual, em interação com uma ou mais barreiras, pode obstruir sua participação plena e efetiva na sociedade em igualdade de condições com as demais pessoas" (BRASIL, 2015, online).

Entretanto, nessa definição, não são consideradas as patologias ou doenças de natureza genética, categoria em que poderiam ser incluídas as pessoas com albinismo, fato que faz com que esses sujeitos sejam incluídos, em sua maioria, no grupo das deficiências de natureza sensorial, devido à sua condição de baixa visão. Inclusão que também se constitui em exclusão e que se revela no tratamento da questão de maneira parcial, ao não considerar outras condições que acometem as pessoas com albinismo e que envolvem, por exemplo, o risco acentuado de desenvolvimento de câncer de pele, algo que evidencia a necessidade ainda maior de problematização desse assunto.

Seguindo essa premissa, uma política de atenção integral à saúde das pessoas com albinismo, em cumprimento aos princípios de equidade e integralidade, deve prevê uma 
linha de cuidado abrangendo atenção primária, de média e alta complexidade integradas em rede, bem como assegurar a multidisciplinariedade das ações.

É necessário que essa rede seja balizada nos princípios, dentre outros, o respeito aos direitos humanos, com garantia de autonomia, independência e de liberdade; a promoção da equidade; promoção do respeito às diferenças e aceitação de pessoas com deficiência, com enfrentamento de estigmas e preconceitos; garantia de acesso e de qualidade dos serviços, ofertando cuidado integral e assistência multiprofissional, sob a lógica interdisciplinar; atenção humanizada e centrada nas necessidades das pessoas; diversificação das estratégias, conforme já estabelecidos para o funcionamento da Rede de Cuidados à Pessoa com Deficiência no Artigo $2^{\circ}$ da Portaria nº 793/2012 do Ministério da Saúde (BRASIL, 2012).

Devido à complexidade do albinismo, que pode afetar ao mesmo tempo a pele e a visão, as pessoas acometidas necessitam de cuidados especiais nos diversos campos de atuação do poder público, principalmente quanto à saúde, educação, acesso ao mercado de trabalho, ao esporte e lazer, dentre outras ações, que lhes possibilitem integração social e melhoria na qualidade de vida, haja vista a intensa desigualdade social sofrida em diferentes dimensões por esses sujeitos.

Urge então a necessidade de maior especificação legal dessa deficiência e das condições que imprimem para as pessoas no que tange à saúde pessoal e ao bem-estar coletivo. Nesse sentido, a Classificação Estatística Internacional de Doenças e Problemas Relacionados à Saúde (CID) - Décima Revisão (CID-10) da Organização Mundial da Saúde (OMS) (ORGANIZAÇÃO MUNDIAL DA SAÚDE, 1993), no seu Capítulo IV, lista o albinismo entre as patologias endócrinas, nutricionais e metabólicas, com o código E70.3, o que constitui um avanço importante que ainda precisa reverberar na legislação brasileira.

Visando uma maior caracterização da condição da pessoa com albinismo, Moreira, Moreira, Cabanelas e Rocha (2007) afirmam que o albinismo diz respeito à transtornos genéticos que atuam na produção de melanina, causando sua redução ou ausência no corpo e que estão relacionados à baixa pigmentação da pele e dos pelos dos cabelos e olhos. Ainda segundo as autoras e o autor, devido à essa condição, as pessoas 
com albinismo são mais propensas às lesões cancerígenas e ao fotoenvelhecimento precoce, assim como sofrem de baixa visão devido à falta de pigmentação nos olhos.

Não existe cura para o albinismo e o tratamento das doenças decorrentes é feito para toda a vida, sendo extremamente necessário o apoio e intervenção do poder público para que todas as pessoas com albinismo tenham acesso aos medicamentos, protetor solar e outras ações como tratamento dermatológico e oftalmológico, pois, como foi visto, o câncer de pele, entre outras doenças oportunistas, atinge-os em alto grau caso a proteção não seja efetiva.

Ikponwosa Ero, Especialista independente das Nações Unidas para o albinismo, no relatório preliminar da visita que fez ao Brasil, inclusive à Bahia, no período de outubro a novembro de 2019, quanto à necessidade de cuidados específicos com a saúde das pessoas com albinismo, destaca que:

É louvável que os cuidados de saúde primários sejam disponibilizados gratuitamente no país. No entanto, o acesso a médicos especializados tais como oftalmologistas, dermatologistas, pediatras, oncologistas e psicólogos, continua difícil, já que esses profissionais tendem a concentrar-se nos centros urbanos. Além disso, alguns deles se encontram sobrecarregados com pacientes. As pessoas das zonas rurais descreveram o acesso particularmente difícil, já que viagens ao centro da cidade, necessárias para o acesso aos cuidados de saúde lhes custam cerca de $1 / 4$ da sua renda mensal e levam várias horas. Também foi relatado que, por vezes, ao chegar ao centro da cidade, não há disponibilidade de protetor solar ou serviços necessários e muitas vezes essas pessoas têm que passar por um complexo sistema de burocracia. Essas barreiras desincentivam novos esforços e colocam as pessoas afetadas pelo albinismo em maior risco de desenvolver câncer de pele (ERO, 2019, p. 6).

As dificuldades apontadas pela autora se mantêm e, ao longo do tempo, tendem a se intensificar, devido à invisibilidade que as pessoas com albinismo sofrem perante a sociedade e o poder público que faz com que não sejam reconhecidas como válidas as suas necessidades, e isso reverbera na ausência de políticas públicas e de projetos voltados ao cuidado nas mais diferentes etapas da vida, desde o nascimento até a maturidade. Tal compreensão também é compartilhada por Santos, Alves, Morais, Moreira e Silva (2016) quando afirmam que essas dificuldades repercutem também na vida escolar, pessoal e cotidiana e se fazem evidentes nas dimensões de promoção e prevenção da saúde, na compra de produtos ópticos, dermatológicos e hospitalares com custo elevado e na seguridade social. 
Nessa perspectiva, devido ao desconhecimento da sociedade sobre o tema, as pessoas com albinismo sofrem discriminação dia após dia, que se intensificam quando da ausência de políticas públicas específicas orientadas à superação das necessidades desse público. Desde o nascimento, ainda no berçário, são expostas a dúvidas acerca da paternidade ou da troca dos bebês. Depois são constrangidas quanto à origem social e ao grau de inteligência. Mesmo assim lutam constantemente para que seus direitos básicos sejam respeitados.

\section{Previsão legal do direito}

O conceito de saúde estabelecido pela Carta de Ottawa, em 1986, já ressalta a importância do autocuidado na qualidade de vida do ser humano e, por conseguinte, das pessoas com deficiência, quando cita que:

\footnotetext{
A saúde é construída e vivida pelas pessoas dentro daquilo que fazem no seu dia-a-dia: onde elas aprendem, trabalham, divertem-se e amam. A saúde é construída pelo cuidado de cada um consigo mesmo e com os outros, pela capacidade de tomar decisões e de ter controle sobre as circunstâncias da própria vida, e pela luta para que a sociedade ofereça condições que permitam a obtenção da saúde por todos os seus membros (ORGANIZAÇÃO MUNDIAL DA SAÚDE, 1986, p. 3).
}

Por sua vez, a Convenção das Nações Unidas Sobre os Direitos das Pessoas com Deficiência, que aprovada pelo Congresso Nacional Brasileiro como Emenda Constitucional, estabelece que as pessoas com deficiência têm o direito de gozar o melhor estado de saúde possível, sem discriminação baseada na deficiência, e de ter acesso a serviços de saúde específicos por causa de sua defíciência, inclusive diagnóstico e intervenção precoces, bem como serviços projetados para reduzir ao máximo e prevenir deficiências adicionais, inclusive entre crianças e idosos (BRASIL, 2009a)

Considerando a ausência de dispositivos legais específicos que versem sobre a questão do albinismo e sobre os direitos que as pessoas com albinismo possuem, a análise aqui esboçada se debruça, num primeiro momento, sobre legislações mais amplas relacionadas às pessoas com deficiência, das quais se buscam o embasamento legal que possa contribuir para a efetivação de novas políticas endereçadas a esse público. 
A saúde é direito de todos e dever do Estado, garantido mediante políticas sociais e econômicas que visem à redução do risco de doença e de outros agravos e ao acesso universal e igualitário às ações e serviços para sua promoção, proteção e recuperação. São de relevância pública as ações e serviços de saúde, cabendo ao poder público dispor, nos termos da lei, sobre sua regulamentação, fiscalização e controle, devendo sua execução ser feita diretamente ou através de terceiros e, também, por pessoa física ou jurídica de direito privado, como preveem os artigos 196 e 197 da CF de 1988 (BRASIL, 1988).

Ainda de acordo com a CF é competência comum da União, dos estados, do distrito federal e dos municípios cuidar da saúde e assistência pública, da proteção e garantia das pessoas com deficiência. Até o ano de 2015, os direitos constitucionais das pessoas com deficiência estavam regulamentados por meio de vários instrumentos legais, tais como as leis federais: $n^{\circ} 7.853 / 89$ (sobre o apoio às pessoas com deficiência e sua integração social) (BRASIL, 1989); n 8.080/90 (Lei Orgânica da Saúde) (BRASIL, 1990); $n^{\circ}$ 10.048/00 (BRASIL, 2000a) (estabelecendo prioridades ao atendimento); $n^{\circ}$ 10.098/00 (determinando critérios para a promoção da acessibilidade)(BRASIL, 2000b); os Decretos: 3.298/99 (dispõe sobre a Política Nacional para a Integração da Pessoa com Deficiência) (BRASIL, 1999), $\mathrm{n}^{\circ}$ 5.296/04 (regulamenta as leis $\mathrm{n}^{\circ} 10.048 / 00$ e $\mathrm{n}^{\circ}$ 10.098/00) (BRASIL, 2004), e Decreto 6.949/09 (BRASIL, 2009b) que promulga a Convenção Internacional sobre os Direitos das Pessoas com Deficiência e seu Protocolo Facultativo, assinados em Nova York, em 30 de março de 2007.

O direito à saúde da pessoa com deficiência está regulamentado nos Artigos 18 a 26 do Estatuto da Pessoa com Deficiência (BRASIL, 2015) que, dentre outros direitos, dispõe que é assegurada atenção integral à saúde da pessoa com deficiência em todos os níveis de complexidade, por intermédio do SUS, garantido acesso universal e igualitário.

A Portaria MS/GM no 1.060/02 do Ministério da Saúde (BRASIL, 2002), que aprovou a Política Nacional de Atenção à Saúde da Pessoa com Deficiência, estabelece que é necessário promover a autonomia das pessoas com deficiência, a universalidade de acesso ao SUS, bem como a devida assistência integrada. Define ainda que a política nacional deve adotar o conceito presente no Decreto 3.298/99 (BRASIL, 1999) que considera pessoa com deficiência como "aquela que apresenta, em caráter permanente, perdas ou anormalidades de sua estrutura ou função psicológica, fisiológica ou anatômica, 
que gerem incapacidade para o desempenho de atividades dentro do padrão considerado normal para o ser humano" (BRASIL, 2002, online).

A portaria $\mathrm{n}^{\mathrm{o}} 81$, de 28 de janeiro de 2009 (BRASIL, 2009a) estabelece que o aconselhamento genético é o pilar central da atenção à saúde em genética clínica e deve ser garantido a todos os indivíduos e famílias sob risco de anomalia congênita ou doença genética.

Com base nesses e em outros conceitos, tendo a importância do indivíduo como centro da linha de cuidado na atenção à saúde, o autocuidado deverá estar presente em todo o processo de estruturação dos serviços públicos específicos nos diversos níveis de atenção e durante todo o desenvolver da assistência em saúde. Segundo a Organização Mundial da Saúde (OMS), no preâmbulo da portaria de n. 81, de 20 de janeiro de 2009:

\begin{abstract}
Aproximadamente cinco por cento das gestações resulta no nascimento de uma criança com algum tipo de anomalia congênita ou doença genética que comprometerá seu desenvolvimento e qualidade de vida [...]. As condições de etiologia predominantemente genética respondem por quinze por cento a vinte e cinco por cento das causas de mortalidade perinatal e infantil em nações em desenvolvimento, tendo as anomalias congênitas passado da quinta para a segunda causa de mortalidade infantil no Brasil nos últimos vinte e cinco anos. Existem indicações de que as anomalias congênitas e as doenças geneticamente determinadas têm maior prevalência nos países em desenvolvimento, possivelmente refletindo a falta de medidas preventivas e terapêuticas adequadas (BRASIL, 2009a, online).
\end{abstract}

Entretanto as políticas públicas estabelecidas pela legislação nacional para pessoas com deficiência e para pessoas com doenças raras, não prevê a inclusão das pessoas com albinismo, ressalvado quando diagnosticadas com visão subnormal nos termos da legislação específica. Nesses casos, poderão ter acesso à rede de proteção social ali prevista.

De acordo com a legislação aqui analisada, as pessoas com albinismo se enquadram no segmento das pessoas com deficiência, não pelo albinismo, mas em consequência da doença, por exemplo, quando são diagnosticadas com visão subnormal e a fotofobia, que como vimos, são decorrentes da hipopigmentação (inexistência ou insuficiência de melanina) no globo ocular. Tal situação reforça novamente a necessidade de uma maior especificidade legal para enquadramento do albinismo e para a conseguinte construção de políticas públicas para as pessoas que sofrem dessa deficiência, uma vez 
que elas necessitam ser especialmente assistidas, para que possam desenvolver regularmente suas atividades e para que possam viver de maneira digna.

Das iniciativas legislativas em âmbito federal que propõem o reconhecimento de direitos para as pessoas com albinismo, tramitam, atualmente, três Projetos de Lei (PL):

a) PL 8033/2017 que assegura às pessoas com albinismo o exercício de direitos básicos nas áreas de educação, saúde e trabalho cujo andamento está aguardando designação de relator na Comissão de Educação (BRASIL, 2017);

b) PL 4234/2008 que dispõe sobre a criação do Programa Nacional de Prevenção e Combate ao Câncer de Pele, da Semana Nacional de Prevenção e Combate ao Câncer de Pele, da obrigatoriedade de distribuição gratuita de protetor solar pelo SUS e dá outras providências, aguardando designação de relator na Comissão de Finanças e Tributação (BRASIL, 2008);

c) PL 7762/2014 que institui a Política Nacional de Proteção dos Direitos da Pessoa com Albinismo, de autoria do Senado Federal, que estabelece como direitos: o acesso ao atendimento dermatológico, inclusive ao protetor solar e aos medicamentos essenciais, além do tratamento não farmacológico, da crioterapia e da terapia fotodinâmica; o acesso ao atendimento oftalmológico especializado, assim como às lentes especiais e aos demais recursos de tecnologias assistivas - equipamentos óticos e não óticos necessários ao tratamento da baixa visão e da fotofobia (Art. $3^{\circ}$ ). Também estabelece as ações da Política Nacional de Proteção dos Direitos da Pessoa com Albinismo, quais sejam: a elaboração e a implementação de cadastro nacional; a estruturação da linha de cuidados e o estímulo à prática do autocuidado; a organização do fluxo da assistência à saúde; a definição do perfil epidemiológico; a formação e a capacitação de trabalhadores no âmbito do SUS, para lidarem com os diversos aspectos relacionados com a atenção à saúde da pessoa com albinismo, e a qualificação da atenção integral à saúde da pessoa com albinismo (BRASIL, 2014b).

Ressalta-se que o PL 7762 foi originário do Senado Federal e aprovado naquela casa em 2014, quando, então, seguiu para apreciação pela Câmera Federal. Tramita em regime de prioridade desde essa época, e obteve, por unanimidade, parecer favorável na Comissão de Saúde, Seguridade e Família, bem como da Comissão de Finanças e Tributação. 
Analisando a tramitação dos diversos projetos de lei, confirma-se a invisibilidade desse segmento populacional pelo Estado, pois se existe omissão por parte do Poder Executivo, também está caracterizada a inércia do Poder Legislativo, uma vez que o PL 7762/2014 deveria tramitar em regime de prioridade, o que significa que cada comissão deveria obedecer ao prazo regimental de dez sessões. Considerando que a tramitação do projeto está limitada a 03 comissões, significa que deveria tramitar por no máximo 30 sessões. Como já tramita desde 2 de julho de 2014, as pessoas com albinismo que têm urgência de política pública específica estão em compasso de espera há exato sete anos e quatro meses.

\section{Atenção integral à saúde}

A inexistência de políticas públicas no Brasil impõe às pessoas com albinismo uma condição de vulnerabilidade, pois muitas delas, por não terem acesso à prevenção e ao tratamento precoce, especialmente para as lesões pré-malignas e malignas (câncer de pele), quando encontram acesso à rede pública de saúde, muitas das vezes, são submetidas a mutilações de partes do corpo durante a extirpação da lesão. Em alguns casos, a demora no tratamento do câncer leva a pessoa a óbito, ainda em tenra idade, num flagrante desrespeito do direito à vida consagrado no artigo $5^{\circ}$ da CF. As pessoas com albinismo são mil vezes mais suscetíveis a essa doença, e a expectativa de vida para este grupo pode chegar a 33 anos, em função do câncer de pele, uma condição que pode ser facilmente prevenida (ERO, 2019).

As pessoas com albinismo não serão inseridas nas políticas públicas de saúde se não forem observadas as condições para a promoção, proteção e recuperação da saúde estabelecidas nas diretrizes do SUS. Conforme prevê Lei Orgânica da Saúde (8080/90) (BRASIL, 1990), as ações e os serviços que integram o SUS devem ser desenvolvidos de acordo com as diretrizes previstas no art. 198 da $\mathrm{CF}$, obedecendo, dentre outros princípios, a universalidade, equidade e integralidade.

Estabelecido pela $\mathrm{CF}$ como um direito de todos e um dever do Estado, o princípio de universalidade distingue a saúde como um direito do cidadão. Nesse sentido, abrange a cobertura, o acesso e o atendimento nos serviços do SUS, e exprime a ideia de que o Estado tem o dever de prestar esse atendimento a toda população brasileira. A 
integralidade se caracteriza como princípio que atribui à população o direito de atendimento de forma plena em função das suas necessidades, pela articulação de ações curativas e preventivas nos três níveis de assistência. Já por meio da equidade, objetivase diminuir as diferenças sociais, proporcionando atendimento desigual para necessidades desiguais, caracterizado como o princípio de justiça social (PONTES; CESSO; OLIVEIRA; GOMES, 2009).

Dentre os princípios citados, todos com aplicação imprescindível nas definições e implementações das políticas públicas de saúde, destaca-se a equidade. A equidade consiste na adaptação da regra existente à situação ou a um caso específico, observandose os critérios de justiça com igualdade de oportunidades.

Revisitando a Carta de Ottawa, resultante da Primeira Conferência Internacional Sobre Promoção da Saúde realizada na cidade de Ottawa, Canadá, em novembro de 1986, confirma-se já naquela época, a preocupação com a equidade e a integralidade na construção das políticas públicas de saúde, quando orienta que

[...] a política de promoção da saúde combina diversas abordagens complementares, que incluem legislação, medidas fiscais, taxações e mudanças organizacionais. É uma ação coordenada que aponta para a equidade em saúde, distribuição mais equitativa da renda e políticas sociais (ORGANIZAÇÃO MUNDIAL DA SAÚDE, 1986, p. 2).

Orienta ainda que

[...] as ações conjuntas contribuem para assegurar bens e serviços mais seguros e saudáveis, serviços públicos saudáveis e ambientes mais limpos e desfrutáveis.

A política de promoção da saúde requer a identificação e a remoção de obstáculos para a adoção de políticas públicas saudáveis nos setores que não estão diretamente ligados à saúde. O objetivo maior deve ser indicar aos dirigentes e políticos que as escolhas saudáveis são as mais fáceis de realizar (ORGANIZAÇÃO MUNDIAL DA SAÚDE, 1986, p. 2).

Baseando-se nessas premissas, o estabelecimento de um programa de atenção integral à saúde da pessoa com albinismo garantirá melhor qualidade de vida, com atenção multiprofissional desde a promoção de saúde, passando pela atenção curativa e de reabilitação, iniciando com a orientação preventiva, chegando aos procedimentos de maior complexidade, desde o nascimento e por toda vida, considerando-se que o 
albinismo não tem cura. Santos, Pereira, Moreira e Silva (2017) vêm ao encontro desse pensamento quando defendem que:

\begin{abstract}
A lógica de organização do cuidado a grupos populacionais biomedicamente estabelecidos tem dado o contorno deste campo de produção, aproximando, por conta da visão subnormal, as pessoas com albinismo às construções sociais e de saúde comumente atribuídas às pessoas com deficiência. Como efeito, há a invisibilidade das pessoas com albinismo que se tornam visíveis e reconhecidas quando rotuladas como deficientes, por conta da visão subnormal; ou do desenvolvimento do câncer de pele, no lugar no qual a prevenção em saúde não mais surte efeitos diante do risco do adoecimento. A visibilidade das pessoas com albinismo precisa existir em todos os pontos de atenção, ser uma agenda transversal no Sistema Único de Saúde (SUS), ser ampliada e singularizada no campo do cuidado, da existência (SANTOS; PEREIRA; MOREIRA; SILVA, 2017, p. 320).
\end{abstract}

Embora inexistente lei ordinária regulamentando política pública de saúde para as pessoas com albinismo, no Estado da Bahia a Comissão Intergestores Bipartite (CIB) Instituída pela Portaria no 2094 de 21/06/93 do Secretário da Saúde do Estado da Bahia —, espaços estaduais de articulação e pactuação política que objetivam orientar, regulamentar e avaliar os aspectos operacionais do processo de descentralização das ações de saúde, aprovou por meio da Resolução 368/2010, o Programa Estadual de Atenção Integral à Saúde das Pessoas com Albinismo no Estado da Bahia.

Para uma eficaz inserção da pessoa com Albinismo na sociedade em que vive, ações para a divulgação da doença por meio da educação popular devem fazer parte da organização da assistência em saúde. Assim, todo cidadão pode ter acesso ao conhecimento sobre a patologia, o diagnóstico precoce, suas limitações e como minimizar a exclusão que a doença pode promover quando desconhecida. Seguindo essa premissa, Rolim, Barreto, Cruz e Sampaio (2013) defendem que:

\footnotetext{
A participação popular e o controle social em saúde, dentre os princípios do Sistema Único de Saúde (SUS), destacam-se como de grande relevância social e política, pois se constituem na garantia de que a população participará do processo de formulação e controle das políticas públicas de saúde. No Brasil, o controle social se refere à participação da comunidade no processo decisório sobre políticas públicas e ao controle sobre a ação do Estado (ROLIM; BARRETO; CRUZ; SAMPAIO, 2013, p. 140).
} 
Visando o cumprimento da Resolução, o programa a ser implementado, deve tomar por base, no que couber, as diretrizes estabelecidas nas seguintes políticas nacionais de atenção integral a saúde: Pessoa com Deficiência (Portaria ${ }^{\circ}$ 1.060, de 5 de junho de 2002) (BRASIL, 2002); Pessoas com Doenças Raras (Portaria $n^{\circ}$ 199/2014) (BRASIL, 2014a); Genética Clínica (Portaria n ${ }^{\circ}$ 81/2009) (BRASIL, 2009a); Pessoas com Doença Falciforme (Portaria $\mathrm{n}^{\mathrm{o}}$ 1.391, de 16 de agosto de 2005) (BRASIL, 2005).

Com base nas portarias acima referidas, é essencial que uma política pública assegure às pessoas com albinismo a atenção primária por meio dos centros de referência que organizarão e facilitarão o acesso toda vez que as pessoas necessitarem de atenção especializada; elaboração e implantação de protocolos específicos para atendimento médico e dispensação de medicamentos e equipamentos para as pessoas com albinismo; o estabelecimento de um fluxo de encaminhamento pelo centro de referência para a assistência desses pacientes nas diversas especialidades médicas, para o diagnóstico, o acompanhamento e o tratamento das doenças específicas decorrentes do albinismo.

O atendimento integral pressupõe a junção das atividades preventivas e de promoção de saúde, que devem ser priorizadas, com as atividades assistenciais e reparadoras, que também não podem ser prejudicadas. A assistência às pessoas com albinismo, como ocorre com toda patologia, deve privilegiar a ação multiprofissional e multidisciplinar.

\section{Considerações finais}

Mesmo com as limitações da visão e riscos de câncer de pele, as pessoas com albinismo podem viver normalmente, se receberem apoios e recursos apropriados. Essa constatação indica a necessidade de implantação de políticas públicas e de um novo modelo de intervenção na saúde e melhoria na qualidade de vida das pessoas com albinismo, em que é fundamental a prevenção dos efeitos danosos da radiação, que é mais grave em regiões tropicais como o estado da Bahia, bem como na zona rural do país.

Se não for garantido acesso à política pública específica e integral de saúde para prevenção e tratamento, parcela significativa das pessoas poderá ser vitimada, tanto pelo câncer de pele, em alguns casos em estágio bastante avançado. Bem como a perda da 
acuidade visual, podendo chegar à cegueira. Essas sequelas poderão comprometer significativamente a mobilidade, a qualidade de vida, podendo inclusive reduzir a expectativa de vida dessas pessoas.

Percebe-se que a falta de regulamentação das políticas públicas de saúde pode ser minimizada se houver vontade política do Estado, em especial o Executivo e o Legislativo, para assegurar com urgência a conclusão da tramitação do PL 7762/2014, atualmente aguardando Parecer do relator na Comissão de Constituição, Justiça e Cidadania da Câmara dos Deputados para posterior envio para sanção presidencial, uma vez que pelo rito de tramitação em regime de prioridade não depende de aprovação pelo plenário daquela casa legislativa.

Independentemente da aprovação de lei federal sobre a matéria, não há qualquer impedimento à aprovação de leis específicas pelas demais casas legislativas das demais unidades da Federação, nem obstáculo para que governadores e prefeitos estabeleçam programas estaduais ou municipais relativos a programas específicos de saúde, uma vez que estão respaldados tanto na CF de 1988, como na Lei Orgânica da Saúde, Lei 8080/90 (BRASIL, 1990).

Os movimentos de apoio a essa causa pode ser iniciada a nível municipal por meio da sensibilização dos gestores, como também colocar esta demanda de tanta importância nas conferências de saúde para que assim possa tomar uma maior visibilidade perante à população, visto que os albinos historicamente foram silenciados, marginalizados e discriminados. E ainda trabalhar a data alusiva ao Dia Internacional de Conscientização do Albinismo, comemorada no dia 13/06. ${ }^{1}$ A invisibilidade que as pessoas com albinismo sofrem perante a sociedade e o poder público que faz com que as suas necessidades sejam negligenciadas, isso reverbera na ausência de políticas públicas, de projetos voltados para uma melhor qualidade de vida, bem como favorece e acentua o preconceito e a discriminação. Diante desse cenário, defende-se a promoção de uma educação popular junto a representantes de pessoas com albinismo para que suas

\footnotetext{
${ }^{1}$ Segundo a Biblioteca Virtual de Saúde, no dia 13 de junho, é comemorado o Dia Internacional de Conscientização do Albinismo. Disponível em: https://bvsms.saude.gov.br/feitos-para-brilhar-13-6-diainternacional-de-conscientizacao-sobre-o-albinismo/. Acesso em; 17 nov. 2021.
} 
demandas sejam socializadas e compartilhadas nas diversas esferas, no setor da saúde, da educação, no mercado de trabalho, no âmbito político, cultural e social.

\section{Referências}

ASSOCIAÇÃO DAS PESSOAS COM ALBINISMO NA BAHIA. Inclusão das pessoas com albinismo no mercado de trabalho: projeto apresentado à Petrobrás. Salvador: APALBA, 2008. Mimeografado.

BRASIL. Câmara dos Deputados. Projeto de Lei no 8033/2017. Brasília: Câmara dos Deputados, 2017. Disponível em: https://www.camara.leg.br/propostas-legislativas/2143883. Acesso em: 17 nov. 2021.

BRASIL. Lei 13.146, de 06 de julho de 2015, que institui a lei brasileira de inclusão das pessoas com deficiência (Estatuto das Pessoas com Deficiência). Brasília, DF: Presidência da República, [2015]. Disponível em: http://www.planalto.gov.br/ccivil 03/ ato2015-2018/2015/lei/113146.htm. Acesso em: 17 nov. 2021.

BRASIL. Ministério da Saúde. Portaria no 199, de 30 de janeiro de 2014, que institui a Política Nacional de Atenção Integral às Pessoas com Doenças Raras, aprova as Diretrizes para Atenção Integral às Pessoas com Doenças Raras no âmbito do Sistema Único de Saúde (SUS) e institui incentivos financeiros de custeio, 30 jan. 2014a. Disponível em: https://bvsms.saude.gov.br/bvs/saudelegis/gm/2014/prt0199 30 01 2014.html. Acesso em: 17 nov. 2021.

BRASIL. Senado Federal. Projeto de Lei no 7762/2014. Brasília: Câmara dos Deputados, 2014b. Disponível em: https://www.camara.leg.br/proposicoesWeb/fichadetramitacao?idProposicao $=619475$. Acesso em: 17 nov. 2021 .

BRASIL. Ministério da Saúde. Portaria no 793, de 24 de abril de 2012, institui a Rede de Cuidados à Pessoa com Deficiência no âmbito do Sistema Único de Saúde. Brasília: Ministério da Saúde, 24 abr. 2012. Disponível em: https:/bvsms.saude.gov.br/bvs/saudelegis/gm/ 2012/prt0793_24_04_2012.html. Acesso em: 17 nov. 2021.

BRASIL. Ministério da Saúde. Portaria $\mathbf{n}^{\mathbf{0}}$ 81, de 20 de janeiro de 2009, que institui, no âmbito do Sistema Único de Saúde (SUS), a Política Nacional de Atenção Integral em Genética Clínica. Brasília, DF: Ministério da Saúde, 20 jan. 2009a. Disponível em: https://bvsms.saude.gov.br/bvs/saudelegis/gm/2009/prt0081_20_01_2009.html. Acesso em: 17 nov. 2021.

BRASIL. Decreto no 6.949, de 25 de agosto de 2009, que Promulga a Convenção Internacional sobre os Direitos das Pessoas com Deficiência e seu Protocolo Facultativo, assinados em Nova York, em 30 de março de 2007. Brasília, DF: Presidência da República, [2009b]. Disponível em: http://www.planalto.gov.br/ccivil_03/_ato2007-2010/2009/decreto/d6949.htm. Acesso em: 17 nov. 2021.

BRASIL. Câmara dos Deputados. Projeto de Lei no 4234/2008. Brasília: Câmara dos Deputados, 2008. Disponível em: https://www.camara.leg.br/propostas-legislativas/414705. Acesso em: 17 nov. 2021. 
BRASIL. Ministério da Saúde. Portaria n 1.391, de 16 de agosto de 2005, que institui no âmbito do Sistema Único de Saúde, as diretrizes para a Política Nacional de Atenção Integral às Pessoas com Doença Falciforme e outras Hemoglobinopatias, 16 ago. 2005. Disponível em: https://bvsms.saude.gov.br/bvs/saudelegis/gm/2005/prt1391_16_08_2005.html. Acesso em: 17 nov. 2021.

BRASIL. Decreto n 5.296 de 2 de dezembro de 2004, que regulamenta as Leis nos 10.048, de 8 de novembro de 2000, que dá prioridade de atendimento às pessoas que especifica, e 10.098, de 19 de dezembro de 2000, que estabelece normas gerais e critérios básicos para a promoção da acessibilidade das pessoas portadoras de deficiência ou com mobilidade reduzida, e dá outras providências. Brasília, DF: Presidência da República, [2004]. Disponível em: http://www.planalto.gov.br/ccivil_03/_ato2004-2006/2004/decreto/d5296.htm. Acesso em: 17 nov. 2021.

BRASIL. Ministério da Saúde. Portaria $\mathrm{n}^{\mathrm{o}} 1060$, de 5 de junho de 2002, que aprova a Política nacional de saúde da pessoa portadora de deficiência. Brasília, DF: Ministério da Saúde, 5 jun. 2002. Disponível em: https:/bvsms.saude.gov.br/bvs/saudelegis/gm/2002/prt1060_05_06_2002.html. Acesso em: 17 nov. 2021.

BRASIL. Lei n. ${ }^{\circ}$ 10.048, de 8 de novembro de 2000. Dá prioridade de atendimento às pessoas que especifica, e dá outras providências. Brasília, DF: Presidência da República, [2000b]. Disponível em: http://www.planalto.gov.br/ccivil_03/leis/110048.htm. Acesso em: 17 nov. 2021.

BRASIL. Lei n. ${ }^{0}$ 10.098, de 19 de dezembro de 2000. Estabelece normas gerais e critérios básicos para a promoção da acessibilidade das pessoas portadoras de deficiência ou com mobilidade reduzida, e dá outras providências. Brasília, DF: Presidência da República, [2000b]. Disponível em: http://www.planalto.gov.br/ccivil_03/leis/

110098.htm. Acesso em: 17 nov. $\overline{2} 021$.

BRASIL. Decreto no 3.298, de 20 de dezembro de 1999, que regulamenta a Lei no 7.853, de 24 de outubro de 1989, dispõe sobre a Política Nacional para a Integração da Pessoa Portadora de Deficiência, consolida as normas de proteção, e dá outras providências. Brasília, DF: Presidência da República, [1999]. Disponível em: http://www.planalto.gov.br/ccivil_03/decreto/d3298.htm. Acesso em: 17 nov. 2021.

BRASIL. Lei $\mathbf{n}^{0} \mathbf{8 . 0 8 0}$, de 19 de setembro de 1990, que dispõe sobre as condições para a promoção, proteção e recuperação da saúde, a organização e o funcionamento dos serviços correspondentes e dá outras providências. Brasília, DF: Presidência da República, [1990]. Disponível em: http://www.planalto.gov.br/ccivil_03/leis/18080.htm. Acesso em: 17 nov. 2021.

BRASIL. Lei $\mathbf{n}^{\mathbf{0}} \mathbf{7 . 8 5 3}$, de 24 de outubro de 1989, que dispõe sobre o apoio às pessoas portadoras de deficiência, sua integração social, sobre a Coordenadoria Nacional para Integração da Pessoa Portadora de Deficiência - Corde, institui a tutela jurisdicional de interesses coletivos ou difusos dessas pessoas, disciplina a atuação do Ministério Público, define crimes, e dá outras providências. Brasília, DF: Presidência da República, [1989]. Disponível em: http://www.planalto.gov.br/ccivil_03/leis/17853.htm. Acesso em: 17 nov. 2021.

BRASIL. [Constituição (1988)]. Constituição da República Federativa do Brasil. Brasília, DF: Presidência da República, [1988].

ERO, Y. Relatório das conclusões preliminares sobre a sua visita ao Brasil. Site do UNITED NATIONS HUMAN RIGTHS. 2019. Disponível em: https://www.ohchr.org/Documents/Issues/ Albinism/VisitBrazil_Statement_PortugueseVersion.docx. Acesso em: 17 nov. 2021. 
FREIRE-MAIA, N. Teoria da evolução: de Darwim à teoria sintética. Belo Horizonte: Editora Itatiaia, 1988.

FREITAS, F. O.; FREITAS, J. Z. F.; SANTOS, J. A. Albinismo em comunidades indígenas: o fator cultural afetando a prevalência da doença. Comunicado Técnico, Brasília, v. 125, p. 1-7, jul. 2005.

INSTITUTO BRASILEIRO DE GEOGRAFIA E ESTATÍSTICA. Características gerais da população, religião e pessoas com deficiência: censo demográfico, 2010. Rio de Janeiro: IBGE, 2012.

MOREIRA, L. M. A.; PINHEIRO, M. A. L.; REIS, A. S. P.; VIRGENS, C. S.; GÓES, M. F. N. Hereditariedade do albinismo oculocutâneo em um grupo populacional no estado da Bahia. Journal of Health \& Biological Sciences - Revista de Saúde e Ciências Biológicas, Fortaleza, v. 9, n. 1, p. 1-6, 2021. Disponível em: https://periodicos.unichristus.edu.br/jhbs/article/view/3408. Acesso em: 17 nov. 2021.

MOREIRA, L. A.; MOREIRA, S. C.; CABANELAS, I. T. D.; ROCHA; L. M. Perfil do albinismo oculocutâneo no estado da Bahia. Revista de Ciências Médicas e Biológicas - Journal of Medical and Biological Sciences, Salvador, v. 6, n. 1, p. 69-75, jan./abr. 2007. Disponível em: https://periodicos.ufba.br/index.php/cmbio/article/view/4152. Acesso em: 17 nov. 2021.

MOREIRA, L. M. A.; BORGES, V. M.; PINHEIRO, M. A. L; SANTA CECILIA, M. H. M. Taxa elevada de albinismo oculocutâneo no estado da Bahia, região nordeste do Brasil. Jornal Interdisciplinar de Biociência, Teresina, v.4, n.1, p. 10-15, 2019. Disponível em: https://revistas.ufpi.br/index.php/jibi/article/view/8447/5765. Acesso em: 17 nov. 2021.

MOREIRA, L. M. A.; PINHEIRO, M. A. L; BORGES, V. M.; SANTA CECILIA, M. H. M. Estudo sobre albinismo oculocutâneo e etnia negra em bairros e localidades de Salvador-Bahia. Revista de Ciências Médicas e Biológicas, Salvador, v. 15, n. 1, p. 23-26, 2016. Disponível em: https://periodicos.ufba.br/index.php/cmbio/article/view/14224. Acesso em: 17 nov. 2021.

ORGANIZAÇÃO MUNDIAL DE SAÚDE. Carta de Ottawa. Primeira Conferência Internacional Sobre Promoção da Saúde. Ottawa: OMS, novembro de 1986. Disponível em: https://bvsms.saude.gov.br/bvs/publicacoes/carta_ottawa.pdf. Acesso em: 17 nov. 2021.

ORGANIZAÇÃO MUNDIAL DA SAÚDE. Classificação estatística internacional de doenças e problemas relacionados à saúde. 10. revisão. São Paulo: Editora da Universidade de São Paulo, 1993. vol. 1 (versão em português).

ORGANIZAÇÃO DAS NAÇÕES UNIDAS. Declaração Universal dos Direitos Humanos. Resolução $n^{\circ}$ 217A da Assembleia Geral das Nações Unidas. Paris: Assembleia Geral das Nações Unidas, 10 de dezembro de 1948.

OPAS, Organização Pan-americana de Saúde. Classificação Estatística Internacional de Patologias e Problemas Relacionados à Saúde - Décima Revisão (CID-10.

PONTES, A.P.M; CESSO, R.G.D; OLIVEIRA, D.C; GOMES, A.M.T. O princípio de universalidade do acesso aos serviços de saúde: o que pensam os usuários? Escola Anna Nery Revista de Enfermagem, Rio de Janeiro, v. 13, n. 3, p. 500-507, jul./set. 2009. Disponível em: https://www.scielo.br/j/ean/a/FGxx6mRxgRTDNVByFycsMpQ/?format-pdf\&lang-pt. Acesso em: 17 nov. 2021.

ROLIM, L. B.; BARRETO, R.S. CRUZ, L. C.; SAMPAIO, K. J. A. de J. Participação popular e o controle social como diretriz do SUS: uma revisão narrativa. Saúde Debate, Rio de Janeiro, v. 37, 
n. 96, p. 139-147, jan./mar. 2013. Disponível em: https://www.scielo.br/j/sdeb/a/dNgCW9WdJJx7VHV7xWkhSHq/?format=pdf\&lang=pt. Acesso em: 17 nov. 2021.

SANTOS, N. L. P.; ALVES, M. D. M.; MORAIS, D. B.; MOREIRA, T. O.; SILVA, A. L. A. As pessoas com albinismo e a petição para a formulação de política pública - aposta na produção do cuidado à luz de um dispositivo normativo. Revista Saúde em Redes, Porto Alegre, v. 2, n. 1, online, 2016. Suplemento. Disponível em: http://conferencia2016.redeunida.org.br/ocs/index.php/ congresso/2016/paper/view/1966. Acesso em 17 nov. 2021.

SANTOS, N.L.P.; PEREIRA, R. M. M.; MOREIRA, M. C.; SILVA, A.L.A.O cuidado à saúde de pessoas com albinismo: uma dimensão da produção da vida na diferença. Physis: Revista de Saúde Coletiva, Rio de Janeiro, v. 27, n. 2, p. 319-333, abr.jun. 2017. Disponível em: https://www.scielo.br/j/physis/a/6LPdbWtKjcLgMBnBp9mvj7n/?format-pdf\&lang-pt. Acesso em: 17 nov. 2021.

ZAGO, M. A. Quadro mundial das condições, enfermidades e doenças consideradas genéticas. Cadernos de Pesquisa Cebrap, São Paulo, n. 2, p. 3-14, jul. 1994.

Recebido em: 15/07/2021.

Aceito em: 02/11/2021. 